\title{
Gamma Irradiation of Bacillus subtilis Spores in the Presence of Sugars
}

\author{
By A. M. COOK, T. A. ROBERTS AND JEAN P. WIDDOWSON \\ Department of Pharmaceutics, School of Pharmacy, \\ University of London, Brunswick Square, London, W.C. 1
}

(Received 10 April 1963)

\begin{abstract}
SUMMARY
Spores of Bacillus subtilis were gamma-irradiated $\left({ }^{60} \mathrm{Co}\right.$ source) and viable counts performed by surface spread and tube dilution methods. Surface spread counts were greater than tube dilution counts by factors varying from 1.57 to 3.90 (aqueous suspensions) and $2 \cdot 36$ to $6 \cdot 10$ (freezedried). In 8 cases out of 10 there was no significant difference in the regression coefficients of $\log \%$ survivors against radiation dose for the two counting methods under identical conditions of irradiation. Freezedrying from $5 \%(w / v)$ aqueous solutions of glucose, lactose or fructose had a significant protective effect on the radiation resistance of the spores. Freeze-drying from aqueous suspension, or from $5 \%$ maltose had no effect on the resistance.
\end{abstract}

\section{INTRODUCTION}

Hill \& Phillips (1959) used a tube dilution method to assess the inactivation of Bacillus subtilis spores in penicillin by gamma-irradiation, claiming that in 'conventional nutrient plate colony counts' the viable count apparently increased as dilution increased. This was attributed to the presence of an inhibitor of spore germination, the tube dilution method being used to dilute such an inhibitor. Direct comparison of surface spread and tube dilution methods for assessing inactivation of irradiated organisms has not been previously reported, although plating methods are generally used. Freeze-drying from $5 \%$ glucose solution has been shown to have a significant protective effect on $\boldsymbol{B}$. subtilis spores subsequently subjected to gamma-irradiation (Roberts, 1961). This work has now been extended to include maltose and fructose, and the results with glucose and lactose confirmed, by using tube dilution and plate count methods.

\section{METHODS}

Preparation of spore suspension. Bacillus subtilis NCTC 8236 was grown on Lemco agar containing $0.0001 \%$ manganous sulphate, with incubation at $37^{\circ}$ for 14 days. The resultant spores were washed five times with sterile water, heated at $78-80^{\circ}$ for $20 \mathrm{~min}$. to kill vegetative forms, and stored in aqueous suspension at $0-4^{\circ}$.

Media. 'Oxoid' peptone agar, and 'Oxoid' peptone water (Oxo Ltd., London).

Diluent. The diluent for counting suspensions was sterile distilled water.

Solutions. Solutions of carbohydrates $(5 \%, w / v)$ in sterile distilled water were used throughout. Glucose was of 'Analar' quality (British Drug Houses Ltd., London), maltose, lactose and fructose were 'Biochemical Reagents' (Thos. Kerfoot and Co. 
Ltd., Vale of Bardsley, Lancs.). (These solutions will be referred to as ' $5 \%$ glucose', etc.)

Freeze-drying. Samples $(0.1 \mathrm{ml}$.) of spore suspensions in $0.5 \mathrm{ml}$. freeze-drying tubes (B.S.S. 795, 1961) were snap-frozen, and primary-dried over $\mathrm{P}_{2} \mathrm{O}_{5}$ at $0.01 \mathrm{~mm}$. $\mathrm{Hg}$ in an Edwards and Co. Ltd., London, Model L.T. 5 apparatus for 6-8 hr, then maintained over fresh $\mathrm{P}_{2} \mathrm{O}_{5}$ for a further $18 \mathrm{hr}$ at $0.01 \mathrm{~mm}$. $\mathrm{Hg}$. Ampoules were sealed at atmospheric pressure under air.

Irradiation. Samples were irradiated in a 'hot-spot' ${ }^{60} \mathrm{Co}$ source at the Wantage Research Laboratory, A.E.R.E., at a dose-rate of $2 \cdot 68 \times 10^{5} \mathrm{rads} / \mathrm{hr}$.

Ampoules containing spores were stored at $0^{\circ}$ before and after irradiation, which was done at room temperature. Radiation dosimetry was performed by members of the Wantage laboratory staff by the method of oxidation of $\mathrm{Fe}^{2+}$ in $0 \cdot 8 \mathrm{~N}$-sulphuric acid.

\section{Viable count methods}

Spread-plate count. A sample (0.5 ml.) of a suspension containing $40-80$ viable spores (determined by a preliminary count) was spread on the surface of each of six overdried peptone agar plates $\left(20 \mathrm{ml}\right.$.) and incubated at $37^{\circ}$ for not less than $36 \mathrm{hr}$.

Tube dilution count. The method used was that described by Cochran (1950) and Finney (1951) for estimating bacterial populations by dilution series. Twofold dilutions were used. Ten samples of 5 drops from calibrated needles were taken from each dilution, and inoculated into peptone water $(10 \mathrm{ml}$.). Tubes were incubated at $37^{\circ}$ shaken daily, and read at intervals during 2 weeks. Increase in number of positives was never observed after 7 days, and about $90 \%$ of positives were evident after $48 \mathrm{hr}$. Five two-fold dilutions were used for each count planned to give an about average of one organism/sample in the third dilution. This gave about equal numbers of positives and negatives, from which maximum information was obtained.

Table 1. Gamma-irradiation of spores of Bacillus subtilis NCTC 8236, freeze-dried from $5 \%$ glucose

Comparison of the methods of Finney (1951) and Fisher \& Yates (1957) for calculating most probable numbers (MPN) from the same dilution series data.

\begin{tabular}{|c|c|c|c|c|}
\hline \multirow[b]{2}{*}{$\begin{array}{l}\text { Radiation } \\
\text { dose } \\
\left(\operatorname{rads} \times 10^{5}\right)\end{array}$} & \multicolumn{2}{|c|}{ Fisher \& Yates method } & \multicolumn{2}{|c|}{ Finney's method } \\
\hline & MPN & $\begin{array}{c}\text { Survivors } \\
(\%)\end{array}$ & MPN & $\begin{array}{c}\text { Survivors } \\
(\%)\end{array}$ \\
\hline 0 & $1.6948 \times 10^{6}$ & 100 & $1.9257 \times 10^{6}$ & 100 \\
\hline $0 \cdot 66$ & $1 \cdot 1844 \times 10^{6}$ & $69 \cdot 88$ & $1.0346 \times 10^{6}$ & $53 \cdot 73$ \\
\hline $1 \cdot 33$ & $5.9219 \times 10^{5}$ & $34 \cdot 94$ & $5 \cdot 2578 \times 10^{5}$ & $27 \cdot 30$ \\
\hline $2 \cdot 65$ & $2.8296 \times 10^{5}$ & $16 \cdot 70$ & $2.7514 \times 10^{5}$ & $14 \cdot 29$ \\
\hline $\mathbf{3 \cdot 9 7}$ & $6 \cdot 1425 \times 10^{4}$ & $3 \cdot 624$ & $6 \cdot 4648 \times 10^{4}$ & $3 \cdot 35 \%$ \\
\hline $5 \cdot 29$ & $3 \cdot 1067 \times 10^{4}$ & $1 \cdot 833$ & $2 \cdot 2266 \times 10^{4}$ & $1 \cdot 156$ \\
\hline $\begin{array}{l}\text { correlation co } \\
\text { regression coe }\end{array}$ & $\begin{array}{l}\text { cient) } \\
\text { ient rads } \times 10^{-5} \text { ) }\end{array}$ & $\begin{array}{l}-0.9924 \\
-0.3476\end{array}$ & & $\begin{array}{l}-0.9941 \\
-0.3571\end{array}$ \\
\hline
\end{tabular}

Comparison of slopes; calculated ' $d$ ' $=0.2812$, tabulated ' $t$ ' $=2.447$ at $P=0.05$. There is therefore no significant difference in slope.

Calculation of most probable number of viable organisms/ml. Finney (1951) estimated the population density of suspensions of organisms by solving the equation of maximum likelihood by use of a $\log -\log$ transformation. This method is longer 
and more tedious than that of Fisher \& Yates (1957) who showed that $87.7 \%$ of the available information is contained in the total number of positive or negative tubes counted without regard to dilution level. A comparison of identical data by using both the Finney and the Fisher \& Yates methods of calculation (Table 1) resulted in no significant difference in the slopes of the regressions of log $\%$ survivors against radiation dose being established.

The Fisher \& Yates method of calculation of the most probable number (MPN) was therefore used.

Statistical analysis. Results from irradiation experiments were expressed as $\%$ survivors, using counts from unirradiated ampoules as representative of $100 \%$. In every case a plot of log $\%$ survivors against dose was linear. Pairs of calculated regressions were compared by a modified ' $t$ ' rest (Bailey, 1959). Blocks of regression were tested for parallelism by an analysis of variance, and when parallelism was established a further analysis showed whether a common regression line could be plotted (Roberts, 1961).

\section{RESULTS}

A summary of results is given in Table 2 .

It was found (Table 3 ) that in 8 cases out of 10 the regressions of log $\%$ survivors against dose did not differ significantly whether counted by surface-spread or tubedilution counts. Protection after freeze-drying, where it occurred, was evident by either counting method (Table 4). Block analyses of variance were performed only on plate-count results.

\section{Table 2. Survival of Bacillus subtilis Norc 8236 spores after gamma irradiation under various conditions}

Slopes $(b)$ and $\boldsymbol{D}$ values for regressions of $\log \%$ survivors against radiation dose in aqueous and freeze-dried carbohydrates. aq., suspension of spores in $5 \%$ aqueous solution of...; f.d., spores freeze-dried from a $5 \%$ aqueous solution of...; $D$ value, that radiation dose required to decrease viability to $10 \%$ of the initial value.

\begin{tabular}{|c|c|c|c|c|}
\hline \multirow[b]{2}{*}{ Spore suspension treatment } & \multicolumn{2}{|c|}{ Plate counts } & \multicolumn{2}{|c|}{ Tube counts } \\
\hline & $\begin{array}{c}b \\
\left(\operatorname{rads} \times 10^{-5}\right)\end{array}$ & $\begin{array}{c}D \\
\left(\operatorname{rads} \times 10^{5}\right)\end{array}$ & $\begin{array}{c}b \\
\left(\operatorname{rads} \times 10^{-5}\right)\end{array}$ & $\begin{array}{c}D \\
\left(\operatorname{rads} \times 10^{5}\right)\end{array}$ \\
\hline Aqueous suspension & $-0 \cdot 6298$ & $1 \cdot 59$ & -0.5744 & $\mathbf{1 . 7 4}$ \\
\hline f.d. from aqueous suspension & -0.6076 & $1 \cdot 65$ & $-0 \cdot 6462$ & $1 \cdot 55$ \\
\hline aq. maltose & $-0 \cdot 6308$ & $1 \cdot 59$ & $-0 \cdot 6322$ & $1 \cdot 58$ \\
\hline f.d. maltose & -0.5265 & 1.90 & -0.5243 & 1.91 \\
\hline aq. glucose & -0.7135 & $1 \cdot 40$ & -0.5320 & $1 \cdot 88$ \\
\hline f.d. glucose & -0.3962 & $\mathbf{2 \cdot 5 2}$ & $-0 \cdot 3476$ & $\mathbf{2 \cdot 8 8}$ \\
\hline aq. lactose & -0.5607 & $1 \cdot 78$ & -0.5825 & $1 \cdot 72$ \\
\hline f.d. lactose & $-0 \cdot 3177$ & $\mathbf{3} \cdot 15$ & -0.2525 & $\mathbf{3 \cdot 9 6}$ \\
\hline aq. fructose & -0.6748 & $1 \cdot 48$ & $-0 \cdot 6175$ & $1 \cdot 62$ \\
\hline f.d. fructose & -0.2359 & $4 \cdot 24$ & $-0 \cdot 1871$ & $\mathbf{5 \cdot 3 5}$ \\
\hline correlation coefficient $(r)$ & all $>$ & $-0 \cdot 9790$ & all $>$. & $0 \cdot 9800$ \\
\hline
\end{tabular}

For each carbohydrate separate survivor curves were determined thus: (a) irradiated spore suspension by plate count; $(b)$ irradiated spore suspension by tube count; $(c)$ irradiated freeze-dried sample of spores by plate count; $(d)$ irradiated freeze-dried sample of spores by tube count. 
Spores irradiated in aqueous suspension, and freeze-dried from aqueous suspension. The slopes of four survivor curves $(a-d)$ were not significantly different $(F=3 \cdot 73$, $\boldsymbol{P}=0 \cdot 10-0 \cdot 20)$ and could be represented by a common regression line $(F=1 \cdot 15$, $P=$ greater than $0 \cdot 20)$ of slope $-0.6588\left(\operatorname{rads} \times 10^{-5}\right)$.

\section{Table 3. Comparison of counting methods}

Modified ' $t$ ' tests on regressions of log \% survivors against radiation dose determined by plate and tube counts in aqueous and freeze-dried states.

\begin{tabular}{lccccc} 
& \multicolumn{5}{c}{ Calculated ' $d$ ' } \\
\cline { 2 - 6 } *aq. plates versus aq. tubes & $\mathbf{1 . 1 2}$ & Maltose & Glucose & Lactose & Fructose \\
f.d. plates versus f.d. tubes & $\mathbf{0 . 2 6}$ & 0.033 & 3.71 & 0.59 & 0.83 \\
& & & 1.02 & 4.11 & 0.84
\end{tabular}

'Those ' $d$ 's in italics indicate a significant difference between slopes.

* aq. plates, suspension of spores: surface spread-count; aq. tubes, suspension of spores : tube dilution count; f.d. plates, spores freeze-dried: surface spread count; f.d. tubes, spores freeze-dried tube-dilution count.

Table 4. Comparison of regressions of log \% survivors against radiation dose in aqueous and freeze-dried states by plate and tube counts

\begin{tabular}{|c|c|c|c|c|c|}
\hline & & & alculated & & \\
\hline & Water & Maltose & Glucose & Lactose & Fructose \\
\hline aq. plates versus f.d. plates & $0 \cdot 31$ & $1 \cdot 99$ & $5 \cdot 83$ & $12 \cdot 98$ & $11 \cdot 88$ \\
\hline q. tubes versus f.d. & 0.53 & $1 \cdot 18$ & $4 \cdot 46$ & $9 \cdot 35$ & $5 \cdot 25$ \\
\hline
\end{tabular}

Those ' $d$ ' $s$ in italics show a significant difference in slopes, indicative of a protective effect upon free-drying.

* aq. plates, suspension of spores : surface spread count; aq. tubes, suspension of spores : tubedilution count; f.d. plates, spores freeze-dried: surface spread count; f.d. tubes, spores freezedried: tube-dilution count.

Spores irradiated in $5 \%$ maltose and freeze-dried from $5 \%$ maltose. The slopes of the four survivor curves were not significantly different $(F=3 \cdot 80, P=0 \cdot 10-0 \cdot 20)$ and could be represented by a common regression line $(F=1 \cdot 16, P>0 \cdot 20)$ of slope $-0.5921\left(\operatorname{rads} \times 10^{-5}\right)$ (Fig. 1).

Spores irradiated in $5 \%$ glucose and freeze-dried from $5 \%$ glucose. The results are shown in Fig. 2. Freeze-drying produced a significant protective effect, but not as great as previously reported (Roberts, 1961). The reason for the less marked protection here is not known. It might be due to slight variation in the conditions of freeze-drying, or the observed increase in radiation resistance of the spore suspension on prolonged storage at $0-4^{\circ}$.

Spores irradiated in $\mathbf{5} \%$ lactose, and freeze-dried from $\mathbf{5} \%$ lactose. A significant protective effect on freeze-drying was shown when the slopes alone were considered (Fig. 3). Extrapolation of the regression for freeze-dried samples to zero irradiation dose indicates that only $4-8 \%$ of the spores were protected. This is almost exactly the previous result. The 'glass' formed by lactose was less obvious than those formed by glucose and fructose. It is possible that only 4-8\% of the spores are actually in the lactose 'glass' and that only these were protected. However, $0.66 \times 10^{5} \mathrm{rads}$ resulted in greater inactivation (96.5\%) in freeze-dried lactose preparations than 
in any other system used. This dose gave mean inactivations of $57 \%$ in water, $66 \%$ in maltose, $66 \%$ in aqueous glucose, and $55 \%$ in aqueous fructose.

Spores irradiated in $\mathbf{5} \%$ fructose and freeze-dried from $\mathbf{5} \%$ fructose. A significant protective effect of freeze-drying was shown (Fig. 4). The degree of protection was estimated by:

$$
\frac{D \text {-value protected (freeze-dried) }}{D \text {-value unprotected (aqueous) }} \text {. }
$$

Values obtained were: glucose, 1·53-1·78; lactose, 1·77-2.30; fructose, $2 \cdot 86-3 \cdot 30$. Although glucose, lactose, and fructose all gave protection on freeze-drying, the regressions were not parallel $(F=9 \cdot 58, P=0 \cdot 001-0 \cdot 01)$.

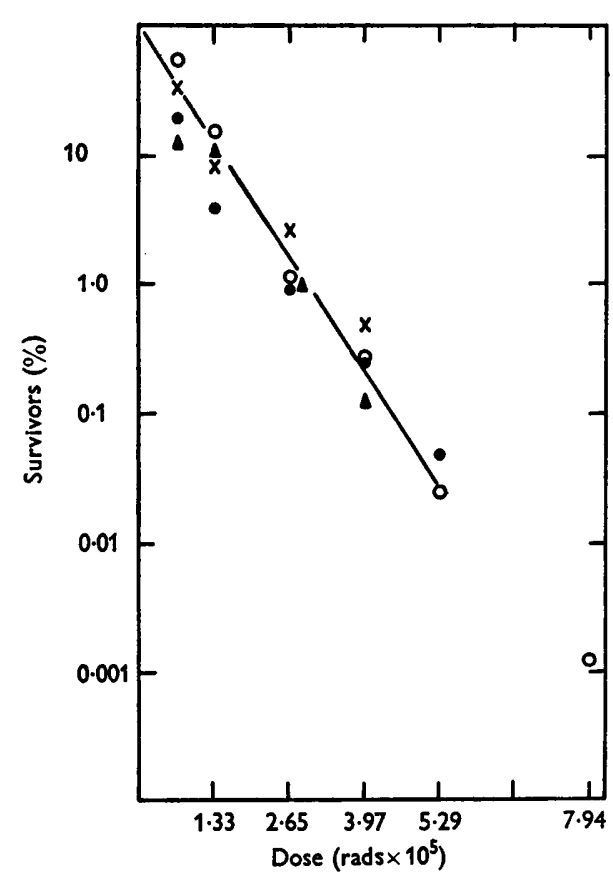

Fig. 1

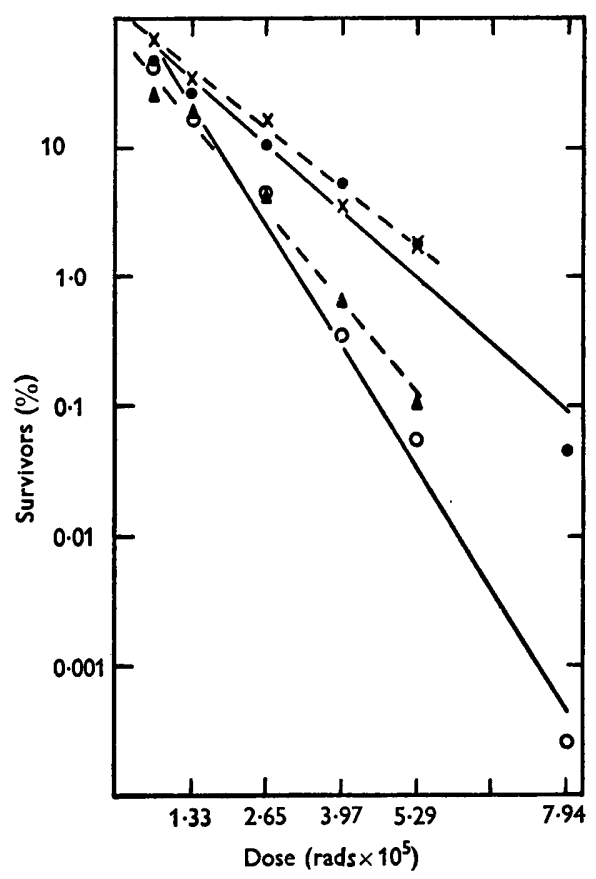

Fig. 2

Fig. 1. - - - Spores freeze-dried from $5 \%$ maltose: surface spread count; - - , spores suspended in $5 \%$ maltose: surface spread count; $--\times-\longrightarrow$, spores freezedried from $5 \%$ maltose: tube-dilution count; - $--\infty$, spores suspended in $5 \%$ maltose: tube-dilution count.

Fig. 2. - - Spores freeze-dried from $5 \%$ glucose: surface spread count; - - spores suspended in $5 \%$ glucose: surface spread count; $-\longrightarrow \times--$, spores freezedried from $5 \%$ glucose: tube-dilution count; - $-\Delta-\longrightarrow$, spores suspended in $5 \%$ glucose: tube-dilution count.

Regressions for the aqueous suspension, those suspensions in aqueous maltose, lactose, glucose and fructose, and the sample freeze-dried from water were parallel $(F=1 \cdot 93, P=0 \cdot 10-0 \cdot 20)$ but could not be represented by a common regression line $(F=9.90, P<0.001)$. Addition of the regression for freeze-dried maltose to the former analysis diminishes the significance level $(F=2 \cdot 24, P=0 \cdot 05-0 \cdot 10)$. 


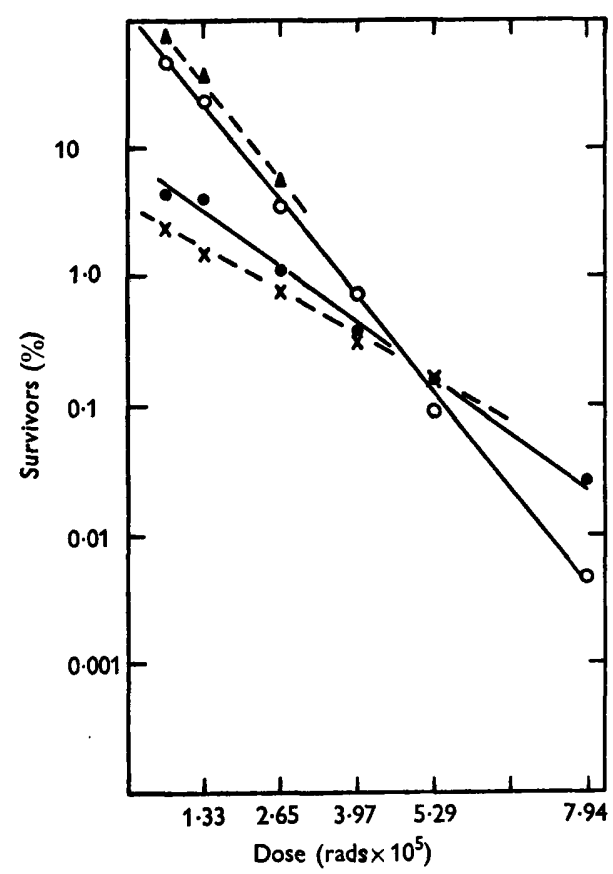

Fig. 3

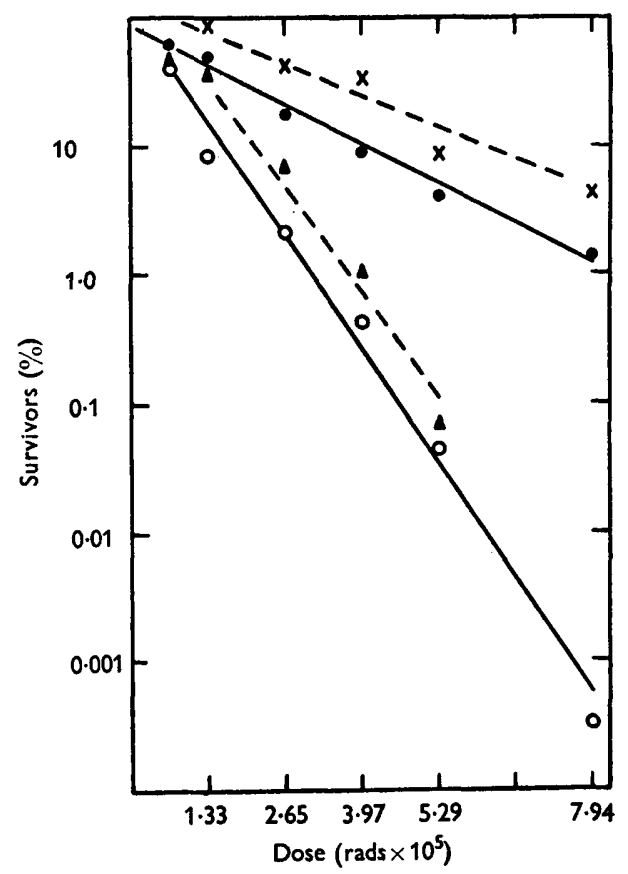

Fig. 4

Fig. 3. - - - Spores freeze-dried from $5 \%$ lactose: surface spread count; $-\bigcirc-$, spores suspended in $5 \%$ lactose: surface spread count; $--\times--$, spores freeze-dried from $5 \%$ lactose: tube dilution count; - $-\Delta-\ldots$, spores suspended in $5 \%$ lactose: tubedilution count.

Fig. 4. - - - Spores freeze-dried from $5 \%$ fructose: surface spread count; - - , spores suspended in $5 \%$ fructose: surface spread count; $--\times-\ldots$, spores freezedried from $5 \%$ fructose : tube-dilution count : - $-1-$, spores suspended in $5 \%$ fructose: tube-dilution count.

\section{DISCUSSION}

It should be borne in mind that, while no significant difference in the slopes of $\log \%$ survivors against dose counted by surface-spread and tube-dilution methods has been established, the actual number of survivors was, with 2 exceptions in 54 cases, greater on plates than in tubes. This is illustrated in Table 5.

Linear log survivor/dose curves have been obtained by Donnellan \& Morowitz (1957) and by Woese (1958) for the radiation inactivation of Bacillus subtilis spores. There is no precedent for the type of protection we found above. Protection was evidently associated with the presence of a glass, since maltose produced no obvious glass and no protection, and fructose produced the most marked glass and the greatest protection. Although glass formation is a well-known phenomenon, its characteristics are not readily available. Freeze-drying solutions of glucose from 1 to $30 \%(\mathrm{w} / \mathrm{v})$ all produced glasses, and presumably should therefore protect. Whether the protection is concentration-dependent has not yet been examined. It has been reported (Proctor, Goldblith, Oberle \& Miller (1955)) that the radiation sensitivity of $B$. subtilis is less in vacuo than in air. Since the glass forms during the 
freeze-drying process, it appears possible that the spores encased in the glass are present in a localized vacuum and exhibit typical in vacuo resistance. In the absence of glass formation (maltose) and in suspensions, spores were irradiated in the presence of air. The protective effect demonstrated in freeze-dried sugars is in each case greater than that shown by Proctor et al. (1955), and it seems unlikely that this is the complete explanation.

Table 5. Plate count/tube count of suspensions of spores of Bacillus subtilis NOTC 8236 in $5 \%$ carbohydrate solutions and samples freeze-dried from $\mathbf{5} \%$ carbohydrate solutions at different irradiation doses

\begin{tabular}{|c|c|c|c|c|c|c|c|c|c|c|c|c|c|c|}
\hline \multirow{3}{*}{$\begin{array}{l}\text { Suspension } \\
\text { medium } \\
\text { Sugar }\end{array}$} & \multirow{2}{*}{\multicolumn{2}{|c|}{$\begin{array}{c}\text { Unir- } \\
\text { radiated }\end{array}$}} & \multicolumn{12}{|c|}{ Radiation dose (rads $\times 10^{5}$ ) } \\
\hline & & & & 67 & & 33 & & & & 97 & & 29 & $\mathbf{a}$ & a \\
\hline & aq. & f.d. & aq. & f.d. & aq. & f.d. & aq. & f.d. & aq. & f.d. & aq. & f.d. & q. & f.d. \\
\hline Wat & 4.05 & $4 \cdot 28$ & $\mathbf{2 \cdot 8 6}$ & $\mathbf{3 \cdot 3 1}$ & $2 \cdot 44$ & $2 \cdot 11$ & $1 \cdot 84$ & $\mathbf{2 \cdot 3 6}$ & $2 \cdot 06$ & $1 \cdot 58$ & - & $\mathbf{3 \cdot 5 6}$ & $2 \cdot 55$ & $\mathbf{2 \cdot 8 7}$ \\
\hline Mal & $\mathbf{3 \cdot 2 0}$ & $7 \cdot 05$ & $1 \cdot 40$ & $3 \cdot 97$ & 4.56 & 3.29 & 3.32 & $2 \cdot 46$ & $7 \cdot 02$ & $\mathbf{3 . 5 8}$ & - & - & $\mathbf{3 \cdot 9 0}$ & 4.07 \\
\hline Glucose & 1.98 & $2 \cdot 42$ & $\mathbf{3} \cdot \mathbf{1 5}$ & $1 \cdot 66$ & $1 \cdot 98$ & $1 \cdot 84$ & $1 \cdot 84$ & $1 \cdot 46$ & $1 \cdot 07$ & $\mathbf{5 \cdot 3 8}$ & 1.05 & $\mathbf{2 \cdot 3 7}$ & 1·85 & $2 \cdot 52$ \\
\hline Lact & $\mathbf{2 \cdot 6 0}$ & $3 \cdot 56$ & $\mathbf{1} \cdot \mathbf{6 3}$ & $7 \cdot 38$ & $1 \cdot 68$ & 10.92 & $1 \cdot 63$ & $5 \cdot 88$ & 一 & 4.97 & 一 & 3.91 & $\mathbf{1 \cdot 8 9}$ & $6 \cdot 10$ \\
\hline Tructose & $\mathbf{2 \cdot 7 1}$ & $4 \cdot 40$ & $\mathbf{2 \cdot 3 5}$ & 一 & $0 \cdot 63$ & $\mathbf{2 \cdot 4 3}$ & $0 \cdot 85$ & $1 \cdot 79$ & $1 \cdot 10$ & $1 \cdot 13$ & $1 \cdot 75$ & $2 \cdot 05$ & $1 \cdot 57$ & $\mathbf{2 \cdot 3 6}$ \\
\hline fean & $\mathbf{2 \cdot 9 1}$ & $4 \cdot 34$ & $\mathbf{2 \cdot 2 8}$ & 4.08 & $\mathbf{2 \cdot 2 6}$ & $4 \cdot 12$ & $1 \cdot 80$ & $2 \cdot 79$ & $2 \cdot 79$ & $\mathbf{3 \cdot 3 3}$ & $1 \cdot 40$ & $\mathbf{2 \cdot 9 7}$ & - & 一 \\
\hline
\end{tabular}

Formation of toxic radicals outside the cell may be neglected as a factor in the mechanism of inactivation by ionizing radiations (Davis, 1954; Hutchinson, 1955, 1957). In addition to the 'direct' effect of ionizing radiation, toxic free-radicals produced within spores contribute to their inactivation (Powers, Webb \& Ehret, 1960). The latter damage is dependent upon conditions and may be largely avoided by the prevention of toxic free-radicals reactions. The former is independent of conditions, and is now assumed to include ionizations within 'bound' water (Alexander, 1959) since the water forms an integral part of the protein, and radicals formed within it are not freely diffusible.

No evidence is available to indicate whether the sugar glass forms only outside the spore, or inside the spore wall. High concentrations of glucose external to cells of Saccharomyces cerevisiae led to intracellular dehydration resulting in a marked decrease in radiation sensitivity (Wood, 1959). The importance of intracellular water has also been stressed in work with bacterial spores (Tallentire \& Powers, 1961 ; Webb \& Powers, 1961).

Conflicting results have been reported which suggest that drying may protect against (Moos, 1952) or, when oxygen is present, sensitize to, subsequent irradiation (Tallentire, 1958). Experiments with rigidly controlled water content show sensitization of spores to $\mathbf{X}$ - and gamma-radiation in the presence of, and when stored in the presence of, oxygen. Sensitivity is a function of water content, decreasing sensitivity occurring with increasing water content (Tallentire \& Davies, 1961; Tallentire \& Powers, 1963). Dehydration may therefore explain the sensitization to irradiation of $94 \%$ of the population of spores of Bacillus subtilis in freeze-dried lactose, but does not account for the increased radiation resistance of the remaining $6 \%$, or for the protection afforded to spores in freeze-dried glucose and in freezedried fructose. Further, the reason for sensitization occurring only in freeze-dried 
lactose is obscure. Black \& Gerhardt (1961) showed that B. cereus spores were permeated by glucose, principally by passive diffusion. Formation of a sugar glass within the spore therefore seems possible.

On present evidence the most probable site for the primary cellular lesion of radiation is deoxyribonucleic acid (DNA), no other macromolecule within the cell being so radiation sensitive and so indispensable to the cell. Alexander (1959) stated that reactions causing change in shape or size of macromolecules, such as main-chain scission, or cross-linking, are more likely to cause inactivation than reactions involving slight modification of chemical structure. A cross-linked macromolecular gel structure in the spore core has been proposed by Black \& Gerhardt (1962). Even if glucose is unable to diffuse into this core, glass formation round the core might maintain its integrity and the viability of the spore.

The irradiation of carbohydrates has been the subject of much research, but aqueous solutions have almost always been used (Phillips \& Moody, 1959; Barker, Grant, Stacey \& Ward, 1959). Khenokh, Kuzicheva \& Evdokimov (1961) detected long-life radicals in the crystal lattice up to 1 year after the irradiation of dry carbohydrates. Collins (1962) irradiated 'Analar' samples of carbohydrates, and determined electron spin resonance (ESR) spectra 3 months after irradiation; the results indicated the presence of long-lived radicals. Room-temperature stabilization of organic free-radicals of barbituric acid derivatives in a boric acid glass was reported by Cloutier (1961); carbohydrate glass with similar properties therefore seems possible. The protection would then be due to the prevention of toxic free-radical reactions.

Subsequent work to that reported in this paper, with Escherichia coli $\mathrm{CN} 1539$, in the stationary phase, indicates that surface-spread ('Oxoid' peptone agar) and tube-dilution ('Oxoid' peptone water) counts give nearly identical numerical recoveries. The $D$-value in aqueous suspension was $1.93 \times 10^{4}$ rads. Using $E$. coli CN 1539 a similar protective effect was found after freeze-drying from $5 \%$ glucose $\left(D\right.$-value $\left.8.10 \times 10^{4} \mathrm{rads}\right)$, with no protection either in $5 \%$ glucose $\left(D\right.$-value $1.06 \times 10^{4}$ rads) or after freeze-drying from water $\left(D\right.$-value $1.3 \times 10^{4}$ rads $)$.

\section{REFERENCES}

Alexander, P. (1959). Trans. IXth International Congress on Radiobiology, 2, 966. Ed. by B. Rajewsky. Stuttgart: Thieme.

BaILey, N. J. T. (1959). Statistical Methods in Biology. London: English Universities Press.

Barker, S. A., Grant, P. M., Stacey, M. \& Ward, R. B. (1959). Effects of gamma radiation. Part I. Polymer formation from sugars, hydroxy acids, and amino acids. $J$. chem. Soc. p. 2648.

Black, S. A. \& Gerhardt, P. (1961). Permeability of bacterial spores. I. Characterisation of glucose uptake. J. Bact. 82, 743.

Black, S. A. \& Gerhardt, P. (1962). Permeability of bacterial spores. IV. Water content, uptake, and distribution. J. Bact. 83, 960.

Cloutier, J. A. R. (1961). Room-temperature stabilization of radiation-produced free radicals in barbituric acids. Can. J. Phys. 39, 514.

Cochran, W. G. (1950). Estimation of bacterial densities by means of the 'most probable number.' Biometrics, 6, 105.

Colurss, M. A. (1962). Gamma irradiation damage in monosaccharides. Nature, Lond. $193,1061$.

Davis, M. (1954). Irradiation of bacterial spores with low voltage electrons. Archs. Biochem. 48, 469 . 
Donnellan, J. E. \& Monowitz, H. J. (1957). The irradiation of dry spores of B. subtilis with fast charged particles. Radiat. Res. 7,71 .

FinNey, D. J. (1951). The estimation of bacterial densities by dilution series. J. Hyg. Camb. 49, 26.

Fisher, R. A. \& Yates, F. (1957). Statistical Tables for Biological, Agricultural, and Medical Research, 5th ed. London: Oliver and Boyd.

Hill, E. C. \& Prilurs, G. O. (1959). The inactivation of Bacillus subtilis spores in penicillin by gamma radiation. J. appl. Bact. $22,8$.

HuTchinson, F. (1955). Use of charged particles to measure skin thickness and other surface properties. Ann. N.Y. Acad. Sci. 59, 494.

Hutchinson, F. (1957). The distance that a radical formed by ionizing radiations can diffuse in a yeast cell. Radiat. Res. $7,473$.

Khenokh, M. A. Kuzicheva, E. A. \& Evdokimov, V. F. (1961). The effect of gamma radiation of ${ }^{60} \mathrm{Co}$ on dry carbohydrates. Dokl. obshchem. Sobran. (English translation), 135, 262.

Moos, W. S. (1952). Variation of irradiation effects on micro-organisms in relation to physical changes in their environment. J. Bact. 63, 688.

Phillips, G. O. \& Moody, G. J. (1959). The chemical action of gamma radiation on aqueous solutions of carbohydrates. Int. J. appl. Radiat. $6,78$.

Powers, E. L., Webe, R. B. \& Ehret, C. F. (1960). Storage, transfer, and utilisation of energy from X-rays in bacterial spores. Radiat. Res. Supplement 2, 94.

Proctor, B. E., Goldblith, S. A., Oberle, M. \& Miller, W. C. (1955). Radiosensitivity of B. subtilis under different environmental conditions. Radiat. Res. 3, 295.

RoBerts, T. A. (1961). Studies on the antibacterial activity of gamma rays on spores of Bacillus subtilis. Ph.D. Thesis, University of London.

TALlentrase, A. (1958). An observed oxygen effect during gamma irradiation of dried bacterial spores. Nature, Lond. 182, 1024.

Talinentire, A. \& Davies, D. J. G. (1961). A post-irradiation oxygen effect in bacterial spores and its dependence on water content. Expl Cell Res. 24, 148.

Tallentire, A. \& Powers, E. L. (1961). The participation of bound water in the radiation response of bacterial spores. Radiat. Res. 14, 510 (Abstracts).

Tallentire, A. \& Powers, E. L. (1963). Modification of sensitivity to X-irradiation by water in Bacillus magaterium. Radiat. Res. $20,270$.

Webs, R. B. \& Powers, E. L. (1961). Water, glycerol, and oxygen as factors in the radiation sensitivity of bacterial spores. Radiat. Res. 14, 515 (abstract).

WoEse, C. R. (1958). Comparison of X-ray sensitivity of bacterial spores. J. Bact. 75, 5 .

Wood, T. H. (1959). Inhibition of cell division. Radiat. Res. Supplement 1, 332. 